\title{
MACROPROPAGAÇÃO DE 12 ESPÉCIES ARBÓREAS DA FLORESTA OMBRÓFILA MISTA
}

\author{
Mario Takao Inoue*, Vagner Putton** \\ *Eng. Florestal, Dr., UNICENTRO - takao@irati.unicentro.br \\ **Graduando em Eng. Florestal, UNICENTRO - vagflorest@hotmail.com \\ Recebido para publicação: 31/03/2006 - Aceito para publicação: 14/10/2006
}

\begin{abstract}
Resumo
Estacas obtidas de ramos do ano e de brotação basal de 12 espécies arbóreas da Floresta Nacional de Irati (PR) foram tratadas com ácido indol butírico (AIB) a $3.000 \mathrm{mg} \cdot \mathrm{kg}^{-1}$ e com um enraizante natural comercial (Enraizador Bioflora ${ }^{\mathbb{B}}$ ), visando estudar os seus potenciais de propagação vegetativa. As taxas médias de enraizamento variaram entre $2 \%$ e $69 \%$, sugerindo possibilidades práticas da macropropagação para algumas das espécies testadas. O AIB foi mais eficaz para canela-amarela, enquanto que para canela-sassafrás, erva-mate e pessegueiro-brabo, o enraizante natural propiciou maior taxa de enraizamento. As espécies angico-branco, cambuí, canela-guaicá e guaçatunga mostraram propensão natural ao enraizamento de estacas. Seis das espécies estudadas apresentaram taxas de enraizamento maiores do que $30 \%$, sugerindo a estaquia como alternativa para a multiplicação.
\end{abstract}

Palavras-chave: Enraizamento de estacas; propagação vegetativa; regulador vegetal; AIB; espécies nativas.

\begin{abstract}
Macropropagation of 12 tree species from the mixed ombrophillous forest (Araucaria Forest). Cuttings obtained from current year twigs and from basal sprouts of 12 tree species growing at Floresta Nacional de Irati, Parana State, Brazil, were treated with $3000 \mathrm{mg} \cdot \mathrm{kg}^{-1}$ indole-butyric acid (IBA) and a commercial natural rooting solution (Rooter Bioflora ${ }^{\mathbb{B}}$ ). Rooting of cuttings ranged from $2 \%$ to $69 \%$ suggesting practical possibilities of macropropagation for some of the species. IBA treated cuttings showed better rooting potential for canela-amarela, while for canela-sassafrás, ervamate and pessegueiro-brabo, the natural rooting solution was more efficient. The species angicobranco, cambuí, canela-guaicá and guaçatunga showed a trend for natural rooting. Six of the studied species presented rooting rate greater than $30 \%$ suggesting use of cuttings as an alternative for multiplication.

Keywords: Rooting of cuttings; vegetative propagation; plant growth regulators; IBA; native species.
\end{abstract}

\section{INTRODUÇÃO}

A silvicultura moderna precisa estar sintonizada com as exigências do mercado consumidor de madeiras e de outros produtos florestais. Assim, a semente (ou propágulo) deve apresentar características que propiciem a qualidade exigida do produto final. Por outro lado, a preferência do mercado madeireiro sempre esteve voltada às espécies que, por razões notórias, atualmente estão em processo de escassez ou ameaçadas de extinção. Para tais espécies, é urgente o estudo sobre qualidade e conservação do germoplasma. A alternativa plausível a curto prazo, que garante a conservação da espécie num sistema produtivo de silvicultura clonal, é o desenvolvimento de técnicas de propagação vegetativa.

Atualmente, a silvicultura clonal brasileira, voltada aos eucaliptos e pinus, tem ganhado importância devido às características peculiares obtidas por meio da propagação vegetativa. Já na década de 40 do século passado, Schreiner (1939) apontava vantagens dos clones com referência à uniformidade de crescimento e desenvolvimento e de uma imediata disponibilidade de indivíduos superiores para o reflorestamento. Ferreira (1992) relatou o desenvolvimento histórico da clonagem de Eucalyptus no 
Brasil, que passa inicialmente por um processo de seleção com sementes australianas, seguida de seleção massal nos plantios e posterior propagação vegetativa, iniciada por Poggiani; Suiter (1974).

A propagação vegetativa feita por meio de estacas é um dos métodos mais importantes da macropropagação de espécies florestais e arbustivas ornamentais. Para espécies que podem ser facilmente propagadas por estacas, esse método apresenta numerosas vantagens, dentre as quais a de ser econômico, rápido, simples e não exigir técnicas especiais, como aquelas necessárias para enxertia. Além disso, obtém-se maior uniformidade devido à ausência de variação genética dos progenitores (HOPPE et al., 1999).

Estudos existentes sobre a propagação vegetativa de espécies nativas abrangem uma quantidade pequena de espécies, principalmente se for levada em consideração a composição arbórea da Floresta Ombrófila Mista (FOM). Ela representa uma das formações vegetais típicas do planalto meridional brasileiro (VELOSO et al., 1991), com espécies florestais madeireiras importantes para a economia do país. Dentre elas, algumas estão no rol de espécies ameaçadas de extinção (HATSCHBACH; ZILLER, 1995), seja pelos impactos relacionados à sua exploração, seja pelas suas próprias características ecofisiológicas. Boa parte das espécies madeireiras da FOM apresenta dificuldade de regeneração natural. Dentre elas, pode-se citar a imbuia (Ocotea porosa Ness.), o pinheiro-brasileiro (Araucaria angustifolia (Bert.) O. Ktze.) e a canela-sassafrás (Ocotea odorifera (Vell.) Rohwer), todas de elevado valor econômico e que se encontram ameaçadas de extinção. Auer; Graça (1995) mostram inúmeros fatores como causas que dificultam a regeneração natural da canela-sassafrás. Em função de ocorrer vigorosa brotação das raízes após a exploração da árvore, Inoue et al. (1984) recomendaram o estudo da viabilidade da propagação vegetativa para essa espécie.

A capacidade natural de propagação vegetativa de lenhosas é variada. Para a erva-mate, Medrado; Sturion (2005) não recomendam a estaquia devido à variação entre estacas de plantas diferentes. A resposta à concentração de regulador vegetal também é muito variada. Trabalhando com pau-de-leite (Sapium glandulatum (Vell.) Pax.), Pimenta et al. (2005) observaram taxa máxima de enraizamento de $11,3 \%$ em estacas tratadas com AIB a 6.000 mg. $\mathrm{L}^{-1}$. Anteriormente, Cunha et al. (2004) haviam concluído que a melhor taxa de enraizamento de estacas de pau-de-leite foi de $52 \%$, tratando as estacas com AIB a $6.000 \mathrm{mg} . \mathrm{L}^{-1}$. Estacas de canela-sassafrás tratadas com AIB a $3.000 \mathrm{mg} \mathrm{kg}^{-1} \mathrm{e} \mathrm{um}$ enraizador natural apresentaram taxa de brotação de $22,8 \%$ e $32,3 \%$, respectivamente (INOUE et al., 2004). Oliveira et al. (2003), aplicando AIB em concentrações de $1.500 \mathrm{mg} . \mathrm{L}^{-1}$ e $3.000 \mathrm{mg} . \mathrm{L}^{-1}$ em estacas de pessegueiro (Prunus persica), observaram que a primeira concentração foi suficiente para a obtenção de até 97,2\% de enraizamento. Em quatro clones de Eucalyptus grandis W. Hill ex Maiden, Titon et al. (2003) constataram aumento no índice de enraizamento e de sobrevivência de miniestacas nas dosagens de $1.000 \mathrm{mg} . \mathrm{L}^{-1}$ e $2.000 \mathrm{mg} . \mathrm{L}^{-1}$. Por outro lado, Wendling; Xavier (2005) observaram que a aplicação do AIB em dosagens de $500 \mathrm{mg} . \mathrm{L}^{-1}, 1.500 \mathrm{mg} . \mathrm{L}^{-1}$ e $3.000 \mathrm{mg} . \mathrm{L}^{-1}$ não resultou em aumento no enraizamento e sobrevivência de miniestacas de quatro clones de Eucalyptus grandis, relatando casos de certos níveis de toxidez nas concentrações acima de $500 \mathrm{mg} \cdot \mathrm{L}^{-1}$.

Considerando o já conhecido processo de extinção de algumas das espécies citadas e de outras, justifica-se que estudos visando à propagação sejam mais amplamente realizados. A macropropagação por meio de estacas apresenta-se, neste momento, como uma promissora alternativa de baixo custo.

Objetiva-se, com o presente estudo, investigar o potencial de propagação vegetativa de algumas espécies florestais ameaçadas de extinção e de outras componentes da FOM de importância econômica e/ou ecológica.

\section{MATERIAL E MÉTODOS}

As matrizes das espécies estudadas encontram-se em parcelas permanentes de pesquisa e observação localizadas na Floresta Nacional de Irati, PR. A coleta dos ramos e a confecção das estacas foram executadas no inverno de 2004. Como material para a obtenção das estacas, deu-se preferência aos ramos que se desenvolveram no respectivo ano e brotações epicórmicas basais. As coletas foram feitas em uma até três matrizes, dependendo da espécie, e não houve uma preocupação nesse controle, pois o estudo objetivou inicialmente detectar o potencial de enraizamento. Foram consideradas 12 espécies florestais autóctones da FOM, listadas na tabela 1. 
Tabela 1. Espécies estudadas, seus potenciais usos e freqüência na floresta.

Table 1. Studied species, common and potential uses and frequency in forest.

\begin{tabular}{|c|c|c|c|}
\hline Nome científico & Nome comum & Utilização/autoecologia & Ocorrência \\
\hline $\begin{array}{l}\text { Anadenanthera colubrina } \\
\text { (Vell.) Brenan }\end{array}$ & Angico-branco & $\begin{array}{l}\text { Medicinal e uso geral. Lucífera de } \\
\text { rápido crescimento. }\end{array}$ & Não-abundante \\
\hline Casearia decandra Jacq. & Guaçatunga & $\begin{array}{l}\text { Medicinal e usos gerais. Lucífera, } \\
\text { colonizadora, indicada para RAD e } \\
\text { arborização. }\end{array}$ & Abundante \\
\hline Eugenia involucrata DC. & Cerejeira & $\begin{array}{l}\text { Frutífera, medicinal e uso em } \\
\text { construções. Lucífera, de } \\
\text { crescimento lento, indicada para } \\
\text { arborização. }\end{array}$ & Não-abundante \\
\hline Eugenia sp. & Cambuí & $\begin{array}{l}\text { Energia e arborização. Tolerante, } \\
\text { crescimento lento. }\end{array}$ & Não-abundante \\
\hline Ilex paraguariensis St.-Hil. & Erva-mate & $\begin{array}{c}\text { Medicinal e indústria do mate. } \\
\text { Lucífera, de crescimento moderado. }\end{array}$ & Abundante \\
\hline $\begin{array}{l}\text { Myrsine ferruginea (Ruiz \& } \\
\text { Pav.) Spreng. }\end{array}$ & Capororoca & $\begin{array}{l}\text { Medicinal e uso geral. Lucífera, de } \\
\text { crescimento rápido, indicada para } \\
\text { RAD. }\end{array}$ & Abundante \\
\hline Nectandra lanceolata Ness. & Canela-amarela & $\begin{array}{c}\text { Usos gerais e energia, fácil de } \\
\text { trabalhar. Tolerante, de crescimento } \\
\text { moderado. }\end{array}$ & Rara \\
\hline $\begin{array}{l}\text { Nectandra megapotamica } \\
\text { (Spreng.) Mez }\end{array}$ & Canela-imbuia & $\begin{array}{c}\text { Construção e marcenaria, } \\
\text { medicinal. Tolerante, de } \\
\text { crescimento moderado, indicada } \\
\text { para RAD. }\end{array}$ & Rara \\
\hline $\begin{array}{l}\text { Ocotea odorifera (Vell.) } \\
\text { Rohwer }\end{array}$ & Canela-sassafrás & $\begin{array}{l}\text { Medicinal e industrial. Tolerante, } \\
\text { de crescimento lento. }\end{array}$ & Em extinção \\
\hline $\begin{array}{l}\text { Ocotea porosa (Ness. \& } \\
\text { C.Mart) Barroso }\end{array}$ & Imbuia & $\begin{array}{l}\text { Madeira nobre. Tolerante, de } \\
\text { crescimento lento. }\end{array}$ & Em extinção \\
\hline 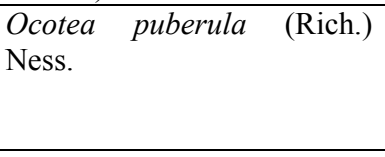 & Canela-guaicá & $\begin{array}{l}\text { Madeira leve para usos gerais, } \\
\text { medicinal. Lucífera colonizadora, } \\
\text { de rápido crescimento, indicada } \\
\text { para RAD. }\end{array}$ & Abundante \\
\hline $\begin{array}{l}\text { Prunus brasiliensis (Scham. } \\
\text { \& Schlecht.) D. Dietrich }\end{array}$ & Pessegueiro-brabo & $\begin{array}{l}\text { Movelaria e usos medicinais. } \\
\text { Lucífera, de crescimento moderado, } \\
\text { indicada para reflorestamento e RAD. }\end{array}$ & Rara \\
\hline
\end{tabular}

RAD: Recuperação de áreas degradadas.

Do material coletado em campo, as amostras para o teste de propagação foram acondicionadas em recipientes contendo solução alcoólica a 5\%, que serviu para a desinfestação inicial, onde ficaram até a chegada ao laboratório, período que se estendeu por cerca de 90 minutos. No laboratório, o material foi imerso em água limpa e submetido à redução de tamanho de estaca para aproximadamente $10 \mathrm{~cm}$ de comprimento, contendo, no mínimo, dois pares de folhas, tendo seus limbos reduzidos à metade de seu tamanho. A desinfestação das estacas foi feita com imersão em solução de hipoclorito de sódio a $0,5 \%$ por cinco minutos. Em seguida, as estacas foram lavadas em água corrente por mais cinco minutos e submetidas a tratamento com fungicida Derosal 0,5 g/litro, por um período de quinze minutos. Após esse processo, as estacas foram enxugadas em papel toalha. Para o teste, foram considerados dois tratamentos com reguladores vegetais: ácido indol butírico (AIB) a $3.000 \mathrm{mg} \cdot \mathrm{kg}^{-1}$ em talco e uma solução enraizadora natural com a denominação comercial Enraizador Bioflora ${ }^{\circledR}$, imergindo-se a base das estacas por cinco minutos. O enraizador natural comercial é produzido por Guimarães Raizer Indústria Química Ltda. (Itajaí, SC, CNPJ: 04.024.575/0001-03) e sua composição não é de conhecimento público. A testemunha consistiu de estacas sem nenhum tratamento. As estacas devidamente preparadas foram plantadas em caixas de material plástico $(35 \times 30 \times 6 \mathrm{~cm})$, contendo vermiculita expandida de granulação média e fina, na proporção de $50 \%$ de cada tipo, em fileiras de 10 estacas. Cada caixa, representando um tratamento, continha 100 estacas, distribuídas em 10 filas de 10 estacas cada uma. As caixas foram levadas à casa-devegetação com nebulização controlada temporalmente para o teste de brotação e enraizamento. A emissão 
de novas brotações foi considerada como resultado positivo, assim como a emissão de primórdios radiciais. Após um período médio de 80 dias de permanência na casa-de-vegetação, as estacas foram retiradas das caixas e foi feita a contagem das que enraizaram. Não foram consideradas as estacas mortas e as que não formaram calosidade. A contagem foi efetuada por fileira, transformada em porcentagem, com posterior transformação para arco-seno da raiz quadrada da porcentagem, para fins de análise estatística. A disposição das caixas dentro da casa de vegetação foi aleatorizada, e a análise da variância foi efetuada como um experimento inteiramente casualizado, com 10 repetições. A comparação entre médias dos tratamentos foi feita pelo teste de Tukey a 5\%.

\section{RESULTADOS E DISCUSSÃO}

O potencial de enraizamento das espécies, expresso em percentual, está representado na tabela 2. Ilustração parcial dos resultados é mostrada nas figuras 1 e 2, onde podem ser observadas estacas enraizadas de canela-sassafrás e de guaçatunga, respectivamente.

Tabela 2. Taxa de enraizamento (\%) das espécies estudadas de acordo com os pré-tratamentos.

Table 2. Rooted cuttings (\%) of studied species according to previous treatments.

\begin{tabular}{lccc}
\hline Espécie & Testemunha $^{1}$ & $\mathbf{A I B}^{\mathbf{2}}$ & $\mathbf{E . ~ N}^{\mathbf{}^{3}}$ \\
\hline Angico-branco & $27,3 \mathrm{a}$ & $26,7 \mathrm{a}$ & $13,3 \mathrm{~b}$ \\
Cambuí & $29,3 \mathrm{a}$ & $21,2 \mathrm{a}$ & $18,2 \mathrm{~b}$ \\
Canela-amarela & $14,1 \mathrm{c}$ & $66,7 \mathrm{a}$ & $53,5 \mathrm{~b}$ \\
Canela-guaicá & $36,3 \mathrm{a}$ & $13,1 \mathrm{~b}$ & $30,3 \mathrm{a}$ \\
Canela-imbuia & $0,0 \mathrm{~b}$ & $5,1 \mathrm{a}$ & $2,0 \mathrm{a}$ \\
Canela-sassafrás & $18,2 \mathrm{~b}$ & $21,2 \mathrm{~b}$ & $33,3 \mathrm{a}$ \\
Capororoca & $42,4 \mathrm{~b}$ & $66,7 \mathrm{a}$ & $57,6 \mathrm{ab}$ \\
Cerejeira & $21,2 \mathrm{~b}$ & $27,3 \mathrm{a}$ & $25,2 \mathrm{a}$ \\
Erva-mate & $54,5 \mathrm{~b}$ & $54,5 \mathrm{~b}$ & $68,7 \mathrm{a}$ \\
Guaçatunga & $20,8 \mathrm{a}$ & $11,1 \mathrm{~b}$ & $23,6 \mathrm{a}$ \\
Imbuia & $0,0 \mathrm{~b}$ & $4,0 \mathrm{a}$ & $3,0 \mathrm{a}$ \\
Pessegueiro-brabo & $21,2 \mathrm{~b}$ & $14,1 \mathrm{c}$ & $31,3 \mathrm{a}$ \\
\hline
\end{tabular}

${ }^{1}$ Testemunha: Desprovida de tratamento com regulador vegetal.

${ }^{2}$ AIB: Ácido Indol-butírico $3000 \mathrm{mg} \cdot \mathrm{kg}^{-1}$.

${ }^{3}$ E.N.: Enraizador Bioflora ${ }^{\circledR}$.

Valores por espécie, seguidos da mesma letra na linha, não diferem entre si (probabilidade $<0,05$ ) pelo teste de Tukey.

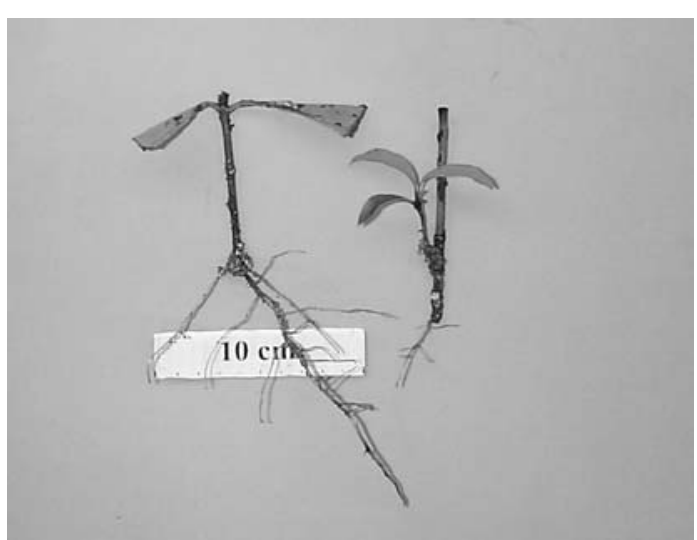

Figura 1. Estacas enraizadas de Ocotea odorifera (canela-sassafrás).

Figure 1. Rooted cuttings of Ocotea odorifera.

Quando comparados com a testemunha, os pré-tratamentos com reguladores vegetais (AIB ou o enraizador natural comercial) promoveram taxas superiores de enraizamento nas estacas de canelaamarela, canela-imbuia, canela-sassafrás, capororoca, cerejeira, erva-mate, imbuia e pessegueiro-brabo. 
Dentre essas, comparando-se os dois pré-tratamentos, as estacas de canela-imbuia, capororoca, cerejeira e imbuia não apresentaram diferenças significativas no enraizamento. Para canela-amarela, o tratamento das estacas com AIB apresentou, no enraizamento, resultados superiores aos do tratamento com o enraizante natural, enquanto que para canela-sassafrás, erva-mate e pessegueiro-brabo, os resultados foram inversos.

As estacas de angico-branco, cambuí, canela-guaicá e guaçatunga que não receberam prétratamento com regulador vegetal (testemunha) apresentaram taxas de enraizamento superiores às das estacas tratadas com AIB ou com o enraizador natural comercial. Dentre essas, as estacas de angicobranco e cambuí não apresentaram diferenças significativas entre a testemunha e o tratamento com AIB, enquanto que para a canela-guaicá e guaçatunga não foram detectadas diferenças entre a testemunha e o tratamento com o enraizante natural. Estacas de pessegueiro-brabo sem tratamento tiveram taxa de enraizamento superior à das estacas tratadas com AIB. Não se observou diferença significante entre a testemunha e o tratamento com AIB no enraizamento de erva-mate.

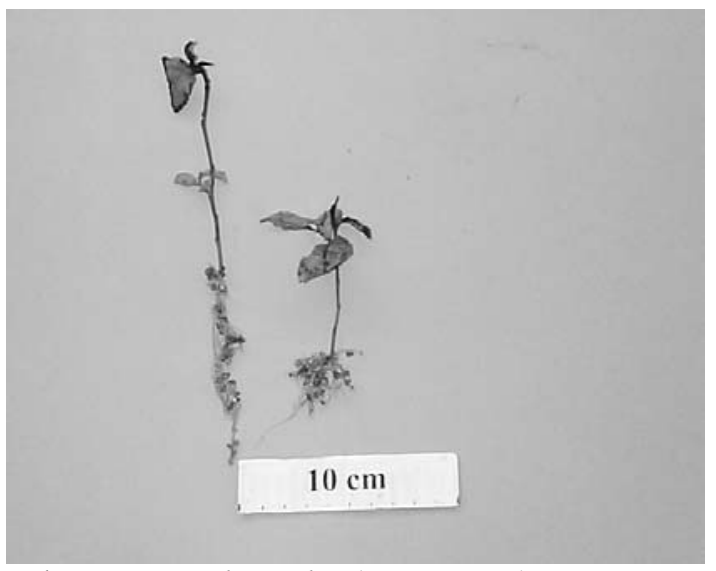

Figura 2. Estacas enraizadas de Casearia decandra (guaçatunga).

Figure 2. Rooted cuttings of Casearia decandra.

Com a porcentagem de estacas enraizadas chegando até $68,7 \%$, o presente estudo mostra viabilidade de uso da macropropagação para algumas das espécies testadas.

Os resultados encontrados por Graça et al. (1988) no tratamento basal de erva-mate com AIB nas concentrações de 5.000 e 8.000 ppm possibilitaram até $62 \%$ e $47 \%$ de enraizamento de estacas, respectivamente. Mesmo sendo menor a concentração do AIB usada no presente estudo, observou-se taxa média de enraizamento de $54,5 \%$. Com média de enraizamento de $68,7 \%$, o enraizador natural comercial utilizado apresenta-se promissor para essa espécie.

As espécies angico-branco, cambuí, canela-sassafrás e erva-mate não apresentaram diferenças entre a testemunha e o tratamento com o AIB. No caso de canela-sassafrás, a aplicação do enraizador natural comercial mostrou ser eficiente, com taxa de enraizamento 57\% superior à do AIB. Tais resultados estão de acordo com a melhor porcentagem de brotação aérea obtida por Inoue et al. (2004) em estacas tratadas com idêntico enraizante natural em comparação à testemunha e ao tratamento com AIB. Esse regulador natural foi também mais eficaz para enraizar estacas de erva-mate e pessegueiro-brabo, do que o AIB e a testemunha.

As estacas de canela-amarela tratadas com AIB apresentaram potencial de enraizamento $25 \%$ superior ao do tratamento com enraizante natural, sugerindo aquela alternativa como método de propagação mais indicado.

Para canela-guaicá, guaçatunga e pessegueiro-brabo, os resultados sugerem efeito inibidor no enraizamento de estacas quando tratadas com AIB, visto que as taxas de enraizamento desse tratamento foram menores do que as da testemunha. Isso pode ser explicado, em parte, de acordo com Xavier et al. (2003), pelo fato de se tratar de material juvenil, no qual o balanço hormonal interno mostra-se favorável ao enraizamento, podendo ocorrer, em certas condições, resposta negativa às aplicações hormonais adicionais. 


\section{CONCLUSÕES}

Pode-se afirmar que existem espécies com propensão natural ao enraizamento de estacas, no presente caso, angico-branco, cambuí, canela-guaicá e guaçatunga. Outras espécies, como canelaamarela, canela-imbuia, canela-sassafrás, capororoca, cerejeira, erva-mate, imbuia e pessegueiro-brabo, apresentam resposta positiva no enraizamento quando tratadas com regulador vegetal.

Metade das espécies estudadas (canela-amarela, canela-guaicá, canela-sassafrás, capororoca, erva-mate e pessegueiro-brabo) apresentou taxas de enraizamento acima de $30 \%$, resultados que indicam a macropropagação por estaquia como alternativa para a multiplicação de tais espécies. Para as demais espécies (angico-branco, cambuí, canela-imbuia, cerejeira, guaçatunga e imbuia), os resultados apontam a necessidade de estudos mais amplos e em maior escala.

\section{REFERÊNCIAS}

AUER, C. G.; GRAÇA, M. E. C. Método para produção de mudas de Canela-sassafrás a partir de mudas de regeneração natural. Boletim de Pesquisa Florestal, Colombo, n. 30/31, p. 75-77, 1995.

CUNHA, A. C. M. C. M.; WENDLING, I.; SOUZA JUNIOR, L. Influência do regulador de crescimento para enraizamento AIB na formação de mudas de Sapium grandulatum (Vell.) Pax por estaquia. Boletim de Pesquisa Florestal, Colombo, n. 49, p. 17-29, 2004.

FERREIRA, M. Melhoramento e a silvicultura intensiva clonal. IPEF, Piracicaba, n. 45. p. 22-30, 1992.

GRAÇA, M. E. C.; COOPER, M. A.; TAVARES, F. R. Estaquia de Erva-mate. EMBRAPA-CNPF, Circular Técnica, Colombo, n. 18, p. 1-6, 1988.

HATSCHBACH, G. G.; ZILLER, S. R. Lista vermelha de plantas ameaçadas de extinção no estado do Paraná. Curitiba: SEMA/GTZ, 1995.

HOPPE, J. M.; SCHUMACHER, M. V.; MIOLA, A. C.; OLIVEIRA, L. S. Influência do diâmetro de estacas no desenvolvimento dos brotos de Platanus $x$ acerifolia. Ciência Florestal, Santa Maria, v. 9, n. 1, p. 25-28, 1999.

INOUE, M. T.; SCHRAIER, P. T.; DINIZ, M. R. Espécies florestais da floresta ombrófila mista ameaçadas de extinção - Canela sassafrás (Ocotea odorifera (Vellozo) Rohwer). Revista da ALACS. Irati, v. 1, n. 1, p. 96-106, 2004.

INOUE, M. T.; RODERJAN, C. V.; KUNIYOSHI, Y. S. Projeto Madeira do Paraná. Curitiba: FUPEF do Paraná, 1984.

MEDRADO, M. J. S.; STURION, J. A. Cultivo da Erva-Mate. Sistemas de Produção, Colombo, n. 1, 2005. Disponível em: < http://sistemasdeproducao.cnptia.embrapa.br $>$ Acesso em: 12 dez. 2005.

OLIVEIRA, A. P.; NIENOW, A. A.; CALVETE, E. O. Capacidade de enraizamento de estacas semilenhosas e lenhosas de cultivares de pessegueiro tratadas com AIB. Revista Brasileira de Fruticultura, Jaboticabal: v. 25, n. 2, p. 282-285, 2003.

PIMENTA, A. C.; ZUFFELlATO-RIBAS, K. C.; OliVEIRA, B. H.; CARPANEZZI, A. A.; KOEHLER, H. S. Interações entre reguladores vegetais, épocas do ano e tipos de substrato no enraizamento de estacas caulinares de Sapium glandulatum (Vell.) Pax. (Pau-de-leite). Boletim de Pesquisa Florestal, Colombo, n. 50, p. 53-67, 2005.

POGGIANI, F.; SUITER, W. Importância da nebulização intermitente e efeito do tratamento hormonal na formação de raízes em estacas de eucalipto. IPEF, Piracicaba, n. 9. p. 119-129, 1974.

SCHREINER, E. J. The possibility of the clone in forestry. Journal of Forestry, Bethesda, v. 37, p. 6162, 1939. 
TITON, M.; XAVIER, A.; OTONI, W. C.; REIS, G. G. Efeito do AIB no enraizamento de miniestacas e microestacas de clones de Eucalyptus grandis W. Hill ex Maiden. Árvore, Viçosa, v. 27, n. 1, p. 1-7, 2003.

VELOSO, H. P.; RANGEL FILHO, A. L. R.; LIMA, J. C. A. Classificação da vegetação brasileira, adaptada a um sistema universal. Rio de Janeiro: IBGE, Departamento de Recursos Naturais e Estudos Ambientais, 1991.

WENDLING, I.; XAVIER, A. Influência do ácido indolbutírico e da miniestaquia seriada no enraizamento e vigor de miniestacas de clones de Eucalyptus grandis. Árvore, Viçosa, v. 29, n. 6, p. 921930, 2005.

XAVIER, A.; SANTOS, G. A.; WENDLING, I.; OLIVEIRA, M. L. D. Propagação de cedro-rosa por miniestaquia. Árvore, Viçosa, v. 27, n. 2, p. 139-143, 2003. 